\title{
Structural Scaffold of 18-Crown-6 Tetracarboxylic Acid for Optical Resolution of Chiral Amino Acid: X-Ray Crystal Analyses of Complexes of D- and L-Isomers of Serine and Glutamic Acid
}

\author{
Hiroomi Nagata, ${ }^{*, a}$ Hiroyuki Nishi, ${ }^{a}$ Miyoko Kamigauchi,${ }^{b}$ and Toshimasa IshidA ${ }^{c}$ \\ ${ }^{a}$ Tanabe Seiyaku Co., Ltd.; 3-16-89 Kashima, Yodogawa-ku, Osaka 532-8505, Japan: ${ }^{b}$ Kobe Pharmaceutical University; \\ 4-19-1 Motoyama-kitamachi, Higashinada-ku, Kobe 658-8558, Japan: and ' Osaka University of Pharmaceutical \\ Sciences; 4-20-1 Nasahara, Takatsuki, Osaka 569-1094, Japan. Received September 6, 2005; accepted January 5, 2006
}

(+)-18-Crown-6 tetracarboxylic acid $\left(\mathbf{1 8 C} 6 \mathrm{H}_{4}\right)$ has been used as a chiral selector for $\mathrm{D} / \mathrm{L}$-amino acids in HPLC, where L-isomer is usually eluted prior to D-isomer, except for the case of serine. To clarify why serine exhibits the reverse order for the elusion, the chiral interactions of D- and L-serines with (+)-18C6 $\mathrm{H}_{4}$ were investigated by the X-ray single crystal analyses, together with the case of $D$ - and L-glutamic acids, which exhibit the usual elution order in HPLC. The backbone structures (amino, $\mathrm{C} \alpha-\mathrm{H}$ and carboxyl groups) of these four amino acids showed the nearly same interaction with $(+)-18 \mathrm{C}^{6} \mathrm{H}_{4}$ despite their different chirality. In contrast, the hydroxyl group of L-serine side chain formed a hydrogen bond with the carboxyl group of $(+)-18 \mathrm{C} \mathrm{H}_{4}$, whereas such a interaction was not formed for the side chain of D-serine and D- and L-glutamic acids. Thus, it was shown that the exception of $\mathrm{D} / \mathrm{L}$-serine from the first elution rule of $\mathrm{L}$-isomer in HPLC is due to the presence and absence of a hydrogen bond formation of its side chain $\mathrm{OH}$ group.

Key words 18-crown-6 tetracarboxylic acid; serine; glutamic acid; crystal structure; complex; chiral interaction

The separation of enantiomers is a subject of great interest, because the biologically effective chiral drug is either of enantiomers and the antipode is regarded as the impurity showing sometime high toxicity. Recently, the HPLC with chiral stationary phases (CSPs) has been extensively used to achieve the direct enantiomer separation. Crown ether, first introduced by Pedersen in $1967,{ }^{1,2)}$ was shown by Cram et $a l^{3,4)}$ to resolve enantiomers by the host-guest complexation. Since then, the optically active crown ether derivatives have been widely used for the optical syntheses, resolutions and analyses of chiral amino compounds. A novel CSP derived from crown ether, which was prepared by immobilizing $(+)$ 18-crown-6 tetracarboxylic acid $\left((+)-18 \mathrm{C} 6 \mathrm{H}_{4}\right)$ on 3 -aminopropylsilanized silica-gel, was reported by Machida et $a l^{5)}$ to show the effective enantiomer separation of amino compounds, and has been widely used as a chiral selector for the primary amines in capillary electrophoresis $(\mathrm{CE})^{6-9)}$ and HPLC. ${ }^{10-12)}$

As for the enantiomer separation of $\mathrm{D} / \mathrm{L}$-amino acids by HPLC with (+)-18C6 $6 \mathrm{H}_{4}$ immobilized CSP, it has been generally accepted that L-isomers are commonly eluted prior to D-amino acids, indicating that $\mathrm{D}$-amino acids form more stable interactions with $(+)-18 \mathrm{C}^{-} \mathrm{H}_{4}$ than L-amino acids. Because no systematic investigation was performed on the discrimination mechanism of $(+)-18 \mathrm{C}^{2} \mathrm{H}_{4}$ between D- and Lisomers, we recently analyzed the crystal structures of the complexes of $(+)-18 \mathrm{C}^{2} \mathrm{H}_{4}$ with $\mathrm{D}$ - and L-isomers of tyrosine, isoleucine, methionine and phenylglycine, and clarified the common structural scaffold of $(+)-18 \mathrm{C} 6 \mathrm{H}_{4}$ for D/L-separation of these chiral amino acids. ${ }^{13)}$

On the other hand, concerning the first elution rule of Lamino acid in $\mathrm{CE}$ with $(+)-18 \mathrm{C} 6 \mathrm{H}_{4}$, an exception was recently observed for the chiral separation of $\mathrm{L} / \mathrm{D}$-serine (Ser). ${ }^{14,15)}$ To clarify why D-Ser is eluted prior to L-Ser, we investigated the chiral interactions of $(+)-18 \mathrm{C} 6 \mathrm{H}_{4}-\mathrm{L}-\mathrm{Ser}(\mathbf{L 1})$ and $(+)-18 \mathrm{C}^{2} \mathrm{H}_{4}-\mathrm{D}-\mathrm{Ser}$ (D1) complexes by the X-ray single crystal analyses. In addition, the crystal structures of $(+)$ $18 \mathrm{C}^{2} \mathrm{H}_{4}-\mathrm{L}$-glutamic acid (L-Glu) $(\mathbf{L 2})$ and $(+)-18 \mathrm{C}^{2} \mathrm{H}_{4}-\mathrm{D}-$ Glu (D2) complexes were also analyzed, as one of the examples according to the first elution rule of $\mathrm{L}$-isomer. In this paper, we report the common as well as different interaction modes between the L- and D-isomers of these two amino acids. The atomic numberings of $(+)-18 \mathrm{C} 6 \mathrm{H}_{4}$, Ser and Glu are given in Fig. 1.

\section{Results and Discussion}

HPLC Analysis The separation data for D-/L-Ser and D/L-Glu are given in Table 1. L-Glu was eluted prior to D-Glu, according to the first elution rule of L-amino acid in HPLC using (+)-18C6 $\mathrm{H}_{4}$ column. ${ }^{5)}$ In the case of Ser, however, the elution order of D- and L-isomers was reversed, and D-isomer
(+)-18C6 $\mathrm{H}_{4}$

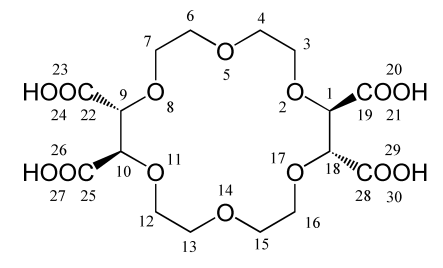

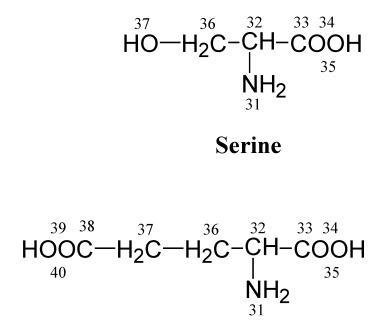

Glutamic Acid
Fig. 1. Chemical Structures and Atomic Numberings Used in This Work

Table 1. Enantiomer Separations of $\mathrm{D} / \mathrm{L}-\mathrm{Ser}$ and $\mathrm{D} / \mathrm{L}-\mathrm{Glu}$ by HPLC Using $(+)-18 \mathrm{C}^{2} \mathrm{H}_{4}$ Column

\begin{tabular}{crc}
\hline \hline & \multicolumn{1}{c}{ Ser } & Glu \\
\hline$k_{1}^{a)}$ & $9.9(\mathrm{D})$ & $10.6(\mathrm{~L})$ \\
$k_{2}{ }^{b)}$ & $13.5(\mathrm{~L})$ & $12.8(\mathrm{D})$ \\
\hline
\end{tabular}

a) Retention time ( $\mathrm{min}$ ) of the first eluted enantiomer. b) Retention time (min) of the second eluted enantiomer. 


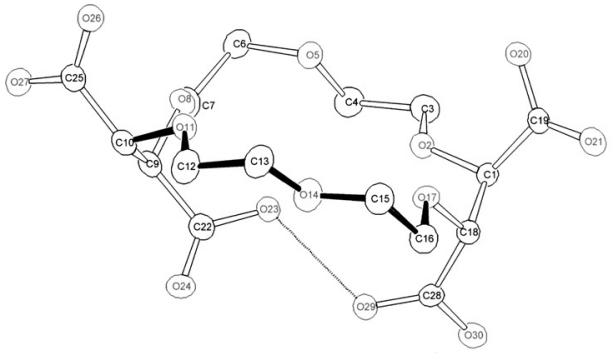

(a)

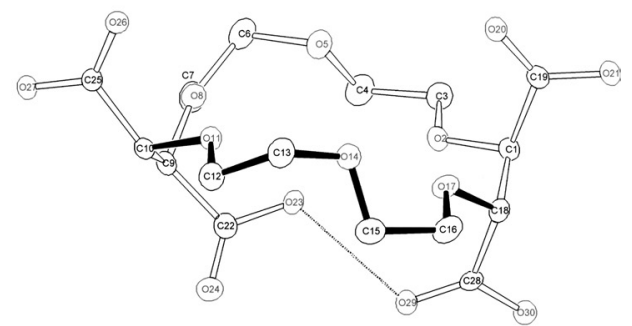

(b)

Fig. 2. Molecular Conformations of (+)-18C6 $\mathrm{H}_{4}$ Observed in $\mathbf{L 1}$ and D1 (a), and L2 and D2 (b)

The C10-O11-C12-C13-O14-C15-C16-O17 sequence is shown with filled bonds. The dotted line represents an intramolecular O23-H $\cdots \mathrm{O} 29$ hydrogen bond between the carboxyl groups.

was eluted before L-isomer. It suggests that the chiral interaction mode of $\mathrm{L}-\mathrm{Ser}$ with $(+)-18 \mathrm{C} 6 \mathrm{H}_{4}$ is more resistant to the elution than that of D-Ser.

X-Ray Crystal Analyses All crystals consist of $1: 1$ complex of $(+)-18 \mathrm{C}^{2} \mathrm{H}_{4}$ with the chiral amino acid. It is characteristic that $\mathbf{L} 1$ complex includes one water molecule and one perchloric ion per asymmetric unit, whereas D1 includes six waters, and L2 and D2 include three water molecules per asymmetric unit.

As for the convex and asymmetric conformation of $(+)-$ $18 \mathrm{C} 6 \mathrm{H}_{4}$ molecule, we previously reported ${ }^{13)}$ that it can be grouped into three types, "conformers I, II and III", according to the orientation around the $\mathrm{C}(10)-\mathrm{O}(11)-\mathrm{C}(12)$ $\mathrm{C}(13)-\mathrm{O}(14)-\mathrm{C}(15)-\mathrm{C}(16)-\mathrm{O}(17)$ bond sequence of crown ether ring (see Fig. 1). According to this conformational classification, the present $(+)-18 \mathrm{C}^{6} \mathrm{H}_{4}$ molecule belongs to conformer I in L1 and D1 (Fig. 2a) and conformer III in D2 and L2 (Fig. 2b). It may say that their conformers are energetically stable and are dependent on the interaction with guest molecule, because the same conformers have also been observed in the complexes with other amine compounds. ${ }^{13,16)}$

All of amino acids took a cationic form, where $\alpha$-amino and $\alpha$-carboxyl groups were protonated and not deprotonated, respectively, and the hydroxyl and $\gamma$-carboxyl groups of chiral Ser and Glu side chains were not deprotonated despite of their different chiralities. The molecular conformations of L- and D-Ser are in the usually observed range. ${ }^{17-19)}$ Some conformational features are; $\psi(\mathrm{N}(31)-\mathrm{C}(32)-\mathrm{C}(33)-$ $\mathrm{O}(34))=-5.2(3)^{\circ}(L 1) / 9.8(2)^{\circ}(D 1), \quad \chi_{1}(\mathrm{~N}(31)-\mathrm{C}(32)-\mathrm{C}(36)-$ $\mathrm{O}(37))=74.5(2)^{\circ}(L 1) /-64.0(2)^{\circ}(D 1), \quad \mathrm{N}(31) \cdots \mathrm{O}(34)=2.703$ (3) $\AA(L 1) / 2.687(3) \AA(D 1), \mathrm{N}(31) \cdots \mathrm{O}(37)=3.040(2) \AA(L 1) /$ $2.868(3) \AA(D l)$. These values with the distances of $\mathrm{N} \cdots \mathrm{O}$ indicate that both L- and D-Ser molecules take a stable conformation through the intramolecular electrostatic interactions of $\alpha$-amino group with $\alpha$-carboxyl group and hydroxyl group of side chain. On the other hand, the torsion angles of L- and D-Glu are $\psi=-61.9(2)^{\circ}(L 2) / 25(1)^{\circ}(D 2), \chi_{1}=-166.9$ $(1)^{\circ}(L 2) / 150.1(6)^{\circ}(D 2), \quad \chi_{2}(\mathrm{C}(32)-\mathrm{C}(36)-\mathrm{C}(37)-\mathrm{C}(38))=$ $177.1(2)^{\circ}(L 2) /-177.4(6)^{\circ}(D 2)$, and $\chi_{3}(\mathrm{C}(36)-\mathrm{C}(37)-\mathrm{C}(38)-$ $\mathrm{O}(39))=-85.2(4)^{\circ}(L 2) /-27(1)^{\circ}(D 2)$, respectively. Although these angles are all in the acceptable region, ${ }^{20-23)}$ the $\psi$ torsion angle of L-Glu was characteristically different from the value $\left(\sim c a .40^{\circ}\right)$ usually observed in the complex with $(+)$ $18 \mathrm{C}_{6} \mathrm{H}_{4}$.

Chiral Interactions of Ser and Glu with $(+)-18 \mathrm{C}^{6} \mathrm{H}_{4}$ The interaction modes between the amino acids and $(+)$ -
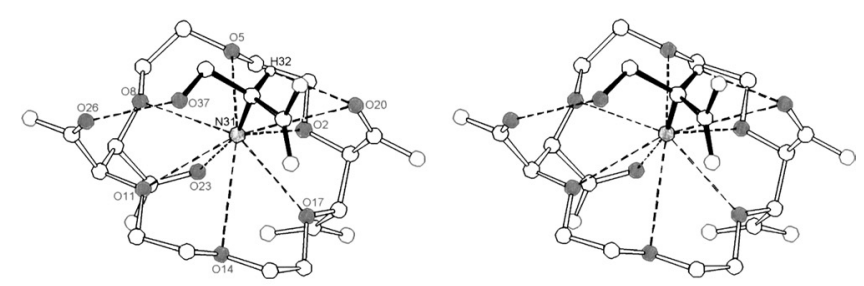

L1
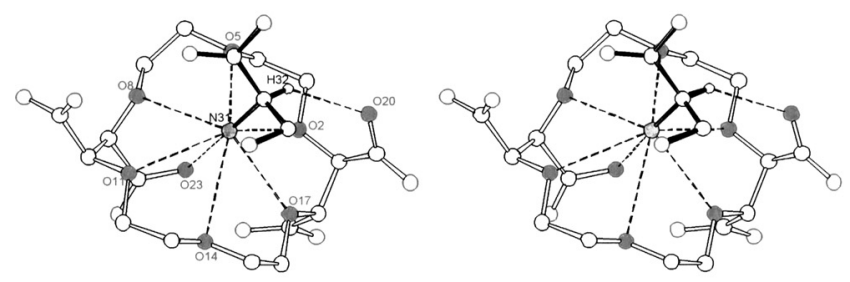

D1
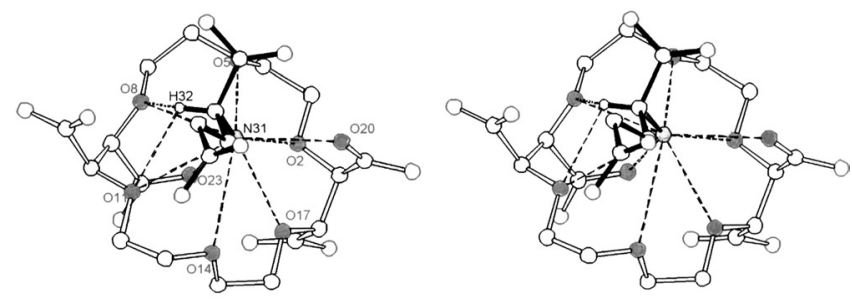

L2
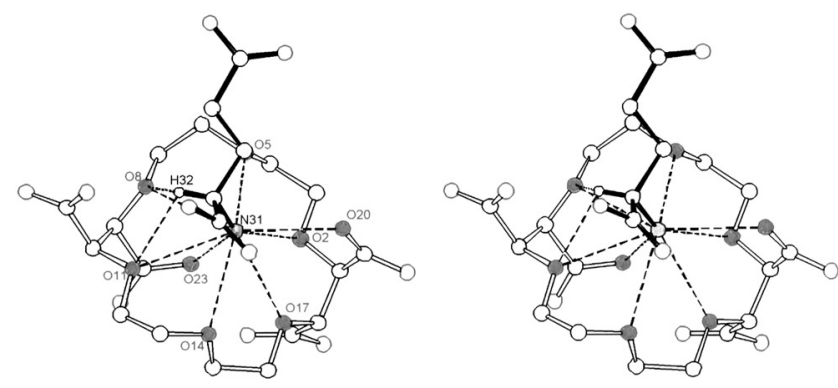

D2

Fig. 3. Stereoscopic Views of Molecular Interactions of L-Ser (L1), D-Ser (D1), L-Glu (L2), and D-Glu (D2) with (+)-18C6H 4 , Viewed Perpendicular to Crown Ether Ring

Amino acids and (+)- $18 \mathrm{C} 6 \mathrm{H}_{4}$ are depicted with filled and open bonds, respectively. Dotted lines represent hydrogen bond or electrostatic interaction.

$18 \mathrm{C} 6 \mathrm{H}_{4}$ observed in the crystal structures of $\mathbf{L 1}, \mathbf{D 1}, \mathbf{L} 2$ and D2 are shown in Fig. 3. Interestingly, the interaction patterns of D-/L-Ser and D-/L-Glu backbone structures (amino-, $\mathrm{C} \alpha-\mathrm{H}$ 
Table 2. Hydrogen Bonds or Electrostatic Interactions $(\AA)$ between N

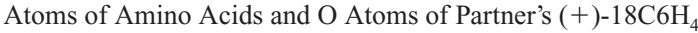

\begin{tabular}{|c|c|c|c|c|}
\hline & L1 & D1 & L2 & D2 \\
\hline $\begin{array}{l}\mathrm{N}(31) \cdots \mathrm{O}(2) \\
\mathrm{N}-\mathrm{H} \cdots \mathrm{O} \\
\angle \mathrm{N}-\mathrm{H} \cdots \mathrm{O}\end{array}$ & $2.966(2)$ & $2.986(2)$ & 3.078 (3) & $3.146(8)$ \\
\hline $\begin{array}{l}\mathrm{N}(31) \cdots \mathrm{O}(5) \\
\mathrm{N}-\mathrm{H} \cdots \mathrm{O} \\
\angle \mathrm{N}-\mathrm{H} \cdots \mathrm{O}\end{array}$ & $\begin{array}{l}3.030(2) \\
2.28 \\
145.3\end{array}$ & $\begin{array}{l}2.905(2)^{a)} \\
2.19 \\
143.1\end{array}$ & $\begin{array}{l}2.877(4) \\
2.05 \\
151.6\end{array}$ & $3.080(8)$ \\
\hline $\begin{array}{l}\mathrm{N}(31) \cdots \mathrm{O}(8) \\
\mathrm{N}-\mathrm{H} \cdots \mathrm{O} \\
\angle \mathrm{N}-\mathrm{H} \cdots \mathrm{O}\end{array}$ & $3.076(2)$ & $\begin{array}{l}2.977(2)^{a)} \\
2.35 \\
132.5\end{array}$ & $3.025(3)$ & $\begin{array}{l}3.151(8)^{b)} \\
2.36 \\
140.9\end{array}$ \\
\hline $\begin{array}{l}\mathrm{N}(31) \cdots \mathrm{O}(11) \\
\mathrm{N}-\mathrm{H} \cdots \mathrm{O} \\
\angle \mathrm{N}-\mathrm{H} \cdots \mathrm{O}\end{array}$ & $\begin{array}{l}2.881(2) \\
2.09 \\
153.1\end{array}$ & $\begin{array}{l}3.009(2) \\
2.15 \\
154.9\end{array}$ & $3.110(3)$ & $2.949(7)$ \\
\hline $\begin{array}{l}\mathrm{N}(31) \cdots \mathrm{O}(14) \\
\mathrm{N}-\mathrm{H} \cdots \mathrm{O} \\
\angle \mathrm{N}-\mathrm{H} \cdots \mathrm{O}\end{array}$ & $3.245(3)$ & $3.138(2)$ & $\begin{array}{l}3.249(4) \\
2.43 \\
156.0\end{array}$ & $\begin{array}{l}2.984(9) \\
2.05 \\
166.2\end{array}$ \\
\hline $\begin{array}{l}\mathrm{N}(31) \cdots \mathrm{O}(17) \\
\mathrm{N}-\mathrm{H} \cdots \mathrm{O} \\
\angle \mathrm{NH} \cdots \mathrm{O}\end{array}$ & $\begin{array}{l}2.982(2) \\
2.13 \\
164.4\end{array}$ & $\begin{array}{l}2.987(2) \\
2.23 \\
172.9\end{array}$ & 3.059 (3) & $3.032(7)$ \\
\hline $\begin{array}{l}\mathrm{N}(31) \cdots \mathrm{O}(20) \\
\mathrm{N}-\mathrm{H} \cdots \mathrm{O} \\
\angle \mathrm{N}-\mathrm{H} \cdots \mathrm{O}\end{array}$ & 3.229 (3) & $\begin{array}{c}(3.803(3)) \\
- \\
-\end{array}$ & $\begin{array}{l}2.824(3) \\
1.88 \\
173.9\end{array}$ & $\begin{array}{l}2.899(8) \\
1.99 \\
160.1\end{array}$ \\
\hline $\begin{array}{l}\mathrm{N}(31) \cdots \mathrm{O}(23) \\
\mathrm{N}-\mathrm{H} \cdots \mathrm{O} \\
\angle \mathrm{N}-\mathrm{H} \cdots \mathrm{O}\end{array}$ & $2.880(3)$ & $2.810(2)$ & $2.972(3)$ & $\begin{array}{l}3.032(8)^{b)} \\
2.23 \\
142.1\end{array}$ \\
\hline
\end{tabular}

$a, b)$ The pair of branched hydrogen bonds.

Table 3. Lengths $(\AA)$ and Angles $\left(^{\circ}\right)$ of $\mathrm{C} \alpha-\mathrm{H} \cdots \mathrm{O}$ Interactions

\begin{tabular}{lllll}
\hline \hline & L1 & D1 & \multicolumn{1}{c}{ L2 } & \multicolumn{1}{c}{ D2 } \\
\hline $\mathrm{C} \cdots \mathrm{O}$ & $2.954(3)^{a)}$ & $3.144(2)^{a)}$ & $3.269(4)^{b)}$ & $3.28(1)^{b)}$ \\
& & & $3.256(4)^{c)}$ & $3.08(1)^{c)}$ \\
$\mathrm{C}-\mathrm{H} \cdots \mathrm{O}$ & 2.47 & 2.38 & 2.73 & 2.69 \\
& & & 2.75 & 2.58 \\
$\angle \mathrm{C}-\mathrm{H} \cdots \mathrm{O}$ & \multirow{2}{*}{107} & \multirow{2}{*}{136} & 117 & 120 \\
& & & 114 & 113 \\
\hline
\end{tabular}

a) $\mathrm{C}(32) \cdots \mathrm{O}(20)$, b) $\mathrm{C}(32) \cdots \mathrm{O}(8), c) \mathrm{C}(32) \cdots \mathrm{O}(11), b-c)$ The pair of branched $\mathrm{C} \alpha-\mathrm{H} \cdots \mathrm{O}$ interactions. and carboxyl groups) with $(+)-18 \mathrm{C} \mathrm{H}_{4}$ are very similar to each other despite their different chiralities, and such similarities were also observed in the Tyr, Ile, Met, and phenylglycine. ${ }^{13)}$

The amino groups of Ser and Glu were located near at the center of the hemisphere of radius $=c a$. $6.0 \AA$, which were created with eight oxygen atoms of crown ether ring and carboxyl group of $(+)-18 \mathrm{C} 6 \mathrm{H}_{4}$, and formed the $\mathrm{N}-\mathrm{H} \cdots \mathrm{O}$ hydrogen bonds and/or $\mathrm{N} \cdots \mathrm{O}$ electrostatic interactions with seven to eight oxygen atoms (Table 2). The $\mathrm{C} \alpha-\mathrm{H}$ groups of all amino acids, on the other hand, participated in the electrostatic interactions with the $\mathrm{O}$ atoms of $(+)-18 \mathrm{C}^{2} \mathrm{H}_{4}$ (Table $3)$. Thus, these $\mathrm{N}-\mathrm{H} \cdots \mathrm{O}$ and $\mathrm{C} \alpha-\mathrm{H} \cdots \mathrm{O}$ interaction patterns of Ser or Glu with $(+)-18 \mathrm{C}^{2} \mathrm{H}_{4}$, which are very similar between the L- and D-enantiomers, form the major stabilizing framework of the host-guest interaction. In contrast, the $\alpha$-carboxyl groups of Ser and Glu did not participate in any interaction with the polar atoms of partner's $(+)-18 \mathrm{C}^{-} \mathrm{H}_{4}$, suggesting that the $\alpha$-carboxyl group of amino acid does not play important role in the chiral recognition of $\mathrm{D} / \mathrm{L}$-amino acid by $(+)-18 \mathrm{C}^{2} \mathrm{H}_{4}$.

On the other hand, a notable difference was observed between L-Ser and the other chiral amino acids concerning the interaction of amino acid side chain with $(+)-18 \mathrm{C}^{2} \mathrm{H}_{4}$. The side chain $\mathrm{OH}$ group of $\mathrm{L}-\mathrm{Ser}$ formed an hydrogen bond with the carboxyl oxygen atom of $(+)-18 \mathrm{C}^{2} \mathrm{H}_{4}[\mathrm{O}(37) \cdots \mathrm{O}(26)=$ $\left.2.714(3) \AA, \mathrm{O}-\mathrm{H} \cdots \mathrm{O}=1.72 \AA, \angle \mathrm{O}-\mathrm{H} \cdots \mathrm{O}=173^{\circ}\right]$, whereas the side chains of D-Ser, D- and L-Glu did not directly form any specific interaction with $(+)-18 \mathrm{C}^{2} \mathrm{H}_{4}$ (see Fig. 3).

Hydrogen bonds of each amino acid with its surrounding molecules in L1, D1, L2 and D2 are summarized in Table 4. The $\alpha$-carboxyl and hydroxyl groups of L-Ser participated in the interactions with the polar atoms of neighboring (+)$18 \mathrm{C}^{2} \mathrm{H}_{4}$, water and the perchloric ion in $\mathbf{~ L 1}$ (Fig. 4), and this is in contrast with those of $\mathrm{D}$-Ser, and L- and D-Glu, which formed the hydrogen bonds only with water molecules in their crystals. On the other hand, perspective views of respective crystal structures are shown in Fig. 5. It is interesting to note that the crystal structures of $\mathbf{L} \mathbf{2}$ and $\mathbf{D} \mathbf{2}$ are very similar

Table 4. Hydrogen Bonds $(\AA)$ of Each Amino Acid with Its Neighboring Molecules Except for $\mathrm{N}-\mathrm{H} \cdots \mathrm{O} / \mathrm{N} \cdots \mathrm{O}$ Interactions

\begin{tabular}{|c|c|c|c|c|c|}
\hline Donor (D-A) & Acceptor (A) & Symmetry code of A & $D \cdots A(\AA)$ & $H \cdots A(\AA)$ & $D-H \cdots A\left(^{\circ}\right)$ \\
\hline \multicolumn{6}{|l|}{ L1 } \\
\hline $\mathrm{O}(37)$ & $\mathrm{O}(26)$ & $x, y, z$ & $2.714(3)$ & 1.72 & 173 \\
\hline $\mathrm{O}(35)$ & $\mathrm{O}(204)^{b)}$ & $x, y, z$ & $2.796(3)$ & 1.89 & 161 \\
\hline $\mathrm{O}(100)^{a)}$ & $\mathrm{O}(34)$ & $x, y, z$ & $2.899(3)$ & 1.94 & 153 \\
\hline $\mathrm{O}(27)$ & $O(37)$ & $-x+1, y-1 / 2,-z$ & $2.662(2)$ & 1.70 & 169 \\
\hline \multicolumn{6}{|l|}{ D1 } \\
\hline $\mathrm{O}(35)$ & $\mathrm{O}(200)^{a)}$ & $x, y, z$ & $2.570(3)$ & 1.53 & 162 \\
\hline $\mathrm{O}(37)$ & $\mathrm{O}(400)^{a}$ & $x, y, z$ & $2.693(2)$ & 1.74 & 154 \\
\hline $\mathrm{O}(100)^{a)}$ & $\mathrm{O}(34)$ & $x, y, z$ & $2.980(3)$ & 2.05 & 157 \\
\hline $\mathrm{O}(300)^{a}$ & $\mathrm{O}(37)$ & $x, y, z$ & $2.874(2)$ & 1.93 & 163 \\
\hline \multicolumn{6}{|l|}{ L2 } \\
\hline O (34) & $\mathrm{O}(300)^{a)}$ & $-x+1, y-1 / 2,-z+1 / 2$ & $2.615(2)$ & 1.67 & 170 \\
\hline $\mathrm{O}(40)$ & $\mathrm{O}(200)^{a)}$ & $-x+1, y+1 / 2,-z+1 / 2$ & $2.621(2)$ & 1.70 & 172 \\
\hline $\mathrm{O}(100)^{a)}$ & $\mathrm{O}(35)$ & $x, y, z$ & $2.909(2)$ & 2.32 & 121 \\
\hline $\mathrm{O}(300)^{a}$ & O (39) & $x, y, z$ & $2.765(3)$ & 2.08 & 156 \\
\hline \multicolumn{6}{|l|}{ D2 } \\
\hline $\mathrm{O}(34)$ & $\mathrm{O}(100)^{a)}$ & $-x+1, y-1 / 2,+z+1 / 2$ & $2.629(9)$ & 1.69 & 169 \\
\hline $\mathrm{O}(40)$ & $\mathrm{O}(200)^{a)}$ & $x, y, z$ & $2.627(1)$ & 1.75 & 162 \\
\hline $\mathrm{O}(100)^{c)}$ & $\mathrm{O}(39)$ & $x, y, z$ & $2.750(9)$ & - & - \\
\hline
\end{tabular}




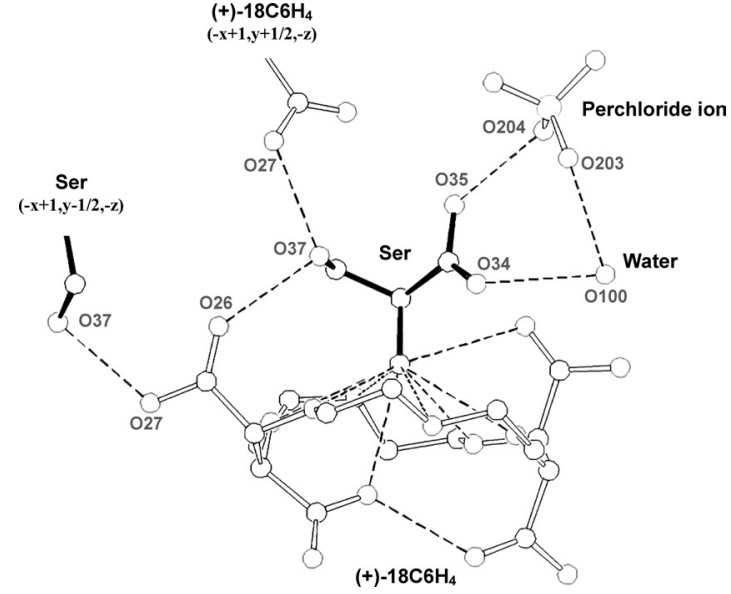

Fig. 4. Perspective View of Interaction Mode of L-Ser with Its Surrounding Molecules in $\mathbf{L 1}$

L-Ser and (+)- $18 \mathrm{C} 6 \mathrm{H}_{4}$ are depicted with filled and open bonds, respectively. Dotted lines represent hydrogen bonds.

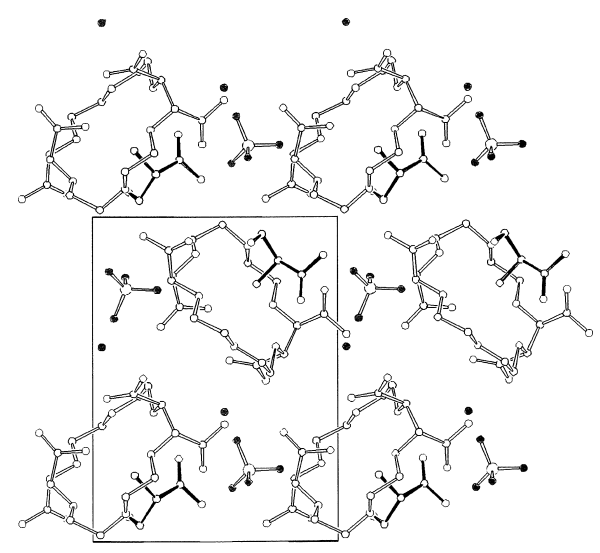

L1

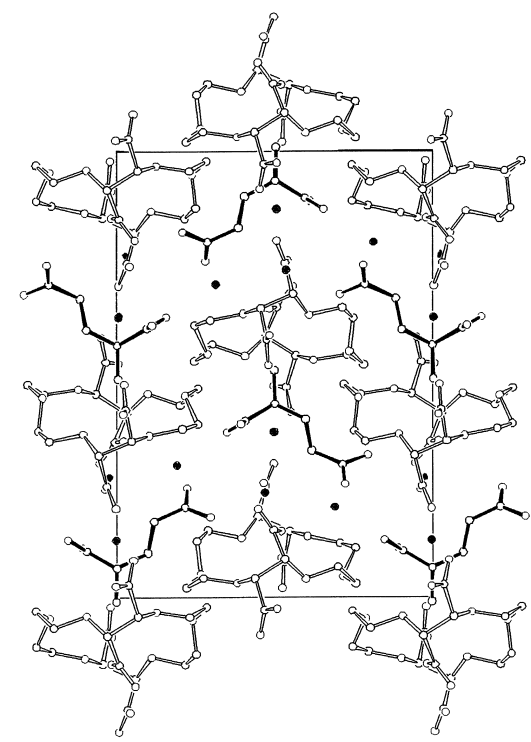

L2 in their unit cell dimensions and crystal packing patterns, and similar molecular arrangement, which is characterized by the spanning with the water layer, is also formed in D1, whereas a notable difference is observed in the molecular packing of L1. This different interaction pattern of L-Ser from the others would affect the reverse order of L-Ser for the elusion in the HPLC.

Structural Scaffold of $(+)-\mathbf{1 8 C} 6 \mathrm{H}_{4}$ for Chiral Separations of $\mathrm{D} / \mathrm{L}-\mathrm{Ser}$ and $\mathrm{D} / \mathrm{L}-\mathrm{Glu}$ On the basis of crystal structure analyses of several $(+)-18 \mathrm{C} 6 \mathrm{H}_{4}$-amino acid complexes reported so far, we proposed a possible chiral separation mechanism $^{13)}$ for the first elution rule of L-amino acid in HPLC using (+)-18C6 $\mathrm{H}_{4}$ column, that is, $(+)-18 \mathrm{C}^{2} \mathrm{H}_{4}$ molecule forms a bowl-shaped figure with two concave and one convex rim, and the location of amino acid on this asymmetric figure leads to the different binding mode between $\mathrm{L}-$ and D-enantiomers, especially for the interaction pattern of the $\mathrm{N}-\mathrm{H}$ and $\mathrm{C} \alpha-\mathrm{H}$ groups with respect to $(+)-18 \mathrm{C}^{2} \mathrm{H}_{4}$, in which the binding energy is advantageous for D-enantiomer rather than L-enantiomer. The schematic binding patterns of

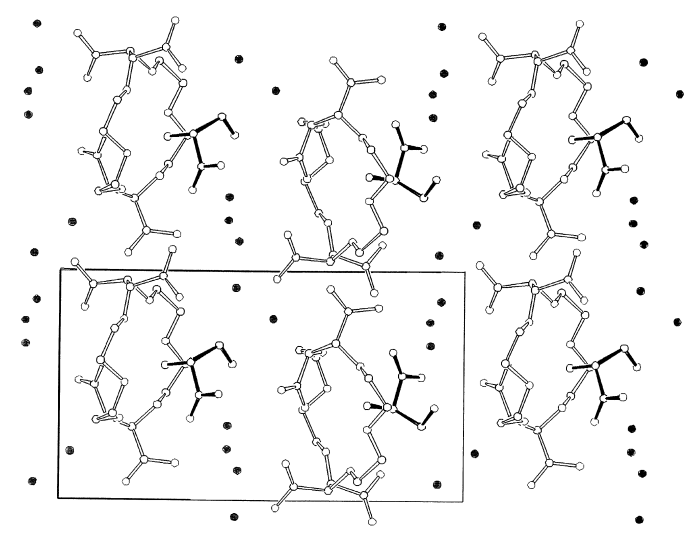

D1

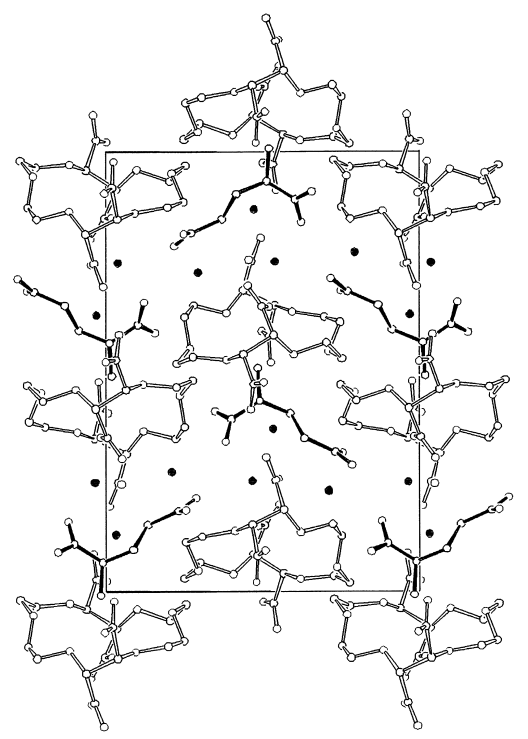

D2

Fig. 5. Complex Crystal Structure, Viewed along $a$-Direction (L1, D1) and $c$-Direction (L2, D2)

Amino acids and $(+)-18 \mathrm{C} \mathrm{H}_{4}$ are depicted with filled and open bonds, respectively. The water molecules and oxygen atoms of perchloride ions are shown with filled circles, respectively. 
L-/D-Ser and L-/D-Glu are shown in Fig. 6. The $\alpha$-carboxyl group of L-Ser and the side chain of D-Ser are located on the big hollow of the bowl, and the $\mathrm{C} \alpha \mathrm{H}$ atoms of $\mathrm{L}-$ and $\mathrm{D}-\mathrm{Ser}$

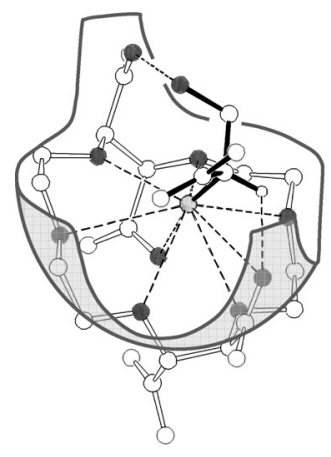

L1

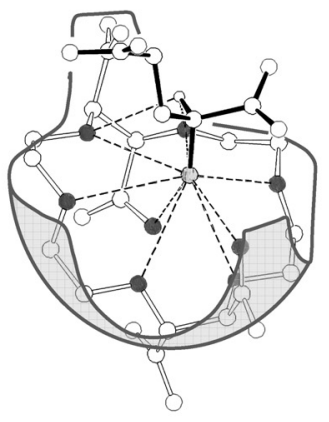

L2

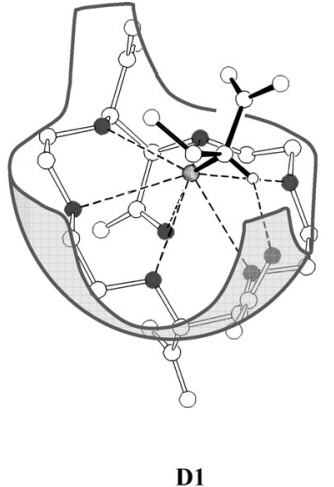

(a)

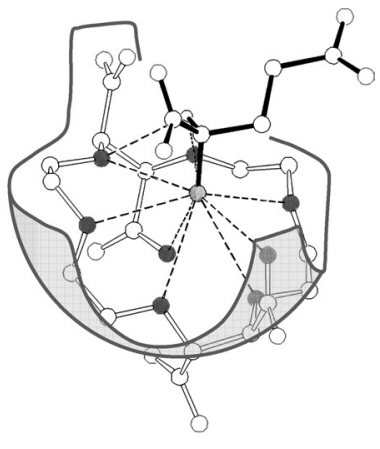

D2 (b)

Fig. 6. Schematic Interaction Patterns of L-/D-Ser (L1, D1) and L-/D-Glu (L2, D2) with (+)-18C6 $\mathrm{H}_{4}$

Dotted lines represent hydrogen bonds or electrostatic interactions. The conformation of $(+)-18 \mathrm{C}^{2} \mathrm{H}_{4}$ could be roughly depicted with a bowl-shaped figure with two concave and one convex rim. are both on the small hollow (Fig. 6a). On the other hand, the $\alpha$-carboxyl groups of L- and D-Glu are located on the small and big hollows of the bowl, respectively, whereas the $\mathrm{C} \alpha \mathrm{H}$ atoms of both enantiomers are commonly directed to the convex wall of the back side of bowl (Fig. 6b).

It would be reasonable to consider that the affinity environment of Glu with (+)-18C6 $\mathrm{H}_{4}$ resin in HPLC is nearly the same between L- and D-enantiomers, as judged from the similar crystal packing and interaction modes of $\mathbf{L} 2$ and D2 (Table 4 and Fig. 5), and the strength of the affinity is primarily dependent on the direct interaction with partner's (+)$18 \mathrm{C} 6 \mathrm{H}_{4}$. Therefore, the elution order of D-/L-Glu suggests that the location of the $\alpha$-carboxyl group and side chain of DGlu on the big and small hollows of the bowl, respectively, is more suitable for the interaction with $(+)-18 \mathrm{C} \mathrm{H}_{4}$ than the reversed location. This agrees with the proposed chiral separation mechanism, ${ }^{13)}$ although no notable preference was suggested between the theoretical total energies of $\mathbf{L 2}$ and D2 complexes (Table 5). On the other hand, the comparison between $\mathbf{L} 1$ and D2 and between D1 and L2 shows similar location of $\alpha$-carboxyl group and side chain on the bowlshaped (+)-18 $66 \mathrm{H}_{4}$, although the location of $\mathrm{C} \alpha-\mathrm{H}$ group is rather different from each other. Thus, it may say that the exception from the first elution rule of L-Ser is partly due to the opposite orientation of $\alpha$-carboxyl group and side chain to that of the L-enantiomer, which obeys the elution rule. Furthermore, the present work clarified that, in addition to the different interaction pattern of L-Ser from the other amino acids in the complex crystals, the major factor determining the elution order of Ser is mostly due to the hydrogen bond formation between the side chain $\mathrm{OH}$ group and the carboxyl

Table 5. Formation Energy and Total Energy of Complex

\begin{tabular}{lcccc}
\hline \hline & L1 & D1 & L2 & D2 \\
\hline Heat of formation, $\mathrm{kcal} / \mathrm{mol}$ & -618.50 & -552.63 & -609.47 & -579.67 \\
Total energy, kcal/mol & -181755 & -181336 & -194304 & -194274 \\
\hline
\end{tabular}

Table 6. Details of Crystal Data, Intensity Collection, and Structure Refinement

\begin{tabular}{|c|c|c|c|c|}
\hline & L1 & D1 & $\mathbf{L 2}$ & D2 \\
\hline Formula & $\begin{array}{l}\mathrm{C}_{16} \mathrm{H}_{24} \mathrm{O}_{14} \\
\cdot \mathrm{C}_{3} \mathrm{H}_{6} \mathrm{NO}_{3}^{+} \\
\cdot \mathrm{H}_{2} \mathrm{O} \cdot \mathrm{ClO}_{4}^{-}\end{array}$ & $\begin{array}{l}\mathrm{C}_{16} \mathrm{H}_{23} \mathrm{O}_{14}^{-} \\
\cdot \mathrm{C}_{3} \mathrm{H}_{6} \mathrm{NO}_{3}^{+} \\
\cdot 6 \mathrm{H}_{2} \mathrm{O}\end{array}$ & $\begin{array}{l}\mathrm{C}_{16} \mathrm{H}_{23} \mathrm{O}_{14}^{-} \\
\cdot \mathrm{C}_{5} \mathrm{H}_{10} \mathrm{NO}_{4}^{+} \\
\cdot 3 \mathrm{H}_{2} \mathrm{O}\end{array}$ & $\begin{array}{l}\mathrm{C}_{16} \mathrm{H}_{23} \mathrm{O}_{14}^{-} \\
\cdot \mathrm{C}_{5} \mathrm{H}_{10} \mathrm{NO}_{4}^{+} \\
\cdot 3 \mathrm{H}_{2} \mathrm{O}\end{array}$ \\
\hline Molecular weight & 663.92 & 653.54 & 641.53 & 641.53 \\
\hline Crystal system & Monoclinic & Monoclinic & Orthorhombic & Orthorhombic \\
\hline $\begin{array}{l}\text { Space group } \\
\text { Unit cell dimensions }\end{array}$ & $P 2_{1}$ & $P 2_{1}$ & $P 2_{1} 2_{1} 2_{1}$ & $P 2_{1} 2_{1} 2_{1}$ \\
\hline$a, \AA$ & $9.504(1)$ & $8.9934(8)$ & $11.549(2)$ & $11.638(2)$ \\
\hline$b, \AA$ & $10.598(1)$ & $16.984(2)$ & $13.123(1)$ & $13.132(2)$ \\
\hline$c, \AA$ & $14.419(2)$ & $10.163(1)$ & $18.907(1)$ & $18.795(3)$ \\
\hline$\alpha,^{\circ}$ & 90 & 90 & 90 & 90 \\
\hline$\beta,^{\circ}$ & $93.720(6)$ & $105.539(6)$ & 90 & 90 \\
\hline$\gamma,{ }^{\circ}$ & 90 & 90 & 90 & 90 \\
\hline Volume, $\AA^{3}$ & $1449.4(3)$ & $1495.5(2)$ & $2865.4(6)$ & $2872.6(9)$ \\
\hline$Z$ & 2 & 2 & 4 & 4 \\
\hline $\mathrm{F}(000)$ & 696.0 & 696.0 & 1360.0 & 1360.0 \\
\hline $\mathrm{Dx}, \mathrm{g} \cdot \mathrm{cm}^{-3}$ & 1.521 & 1.451 & 1.487 & 1.483 \\
\hline$\mu(\mathrm{Cu} K \alpha), \mathrm{cm}^{-1}$ & 20.51 & 11.95 & 11.87 & 11.84 \\
\hline No. of unique data measd & 4728 & 4789 & 5187 & 4984 \\
\hline No. of refrections with $I>3 \sigma(I)$ & 4509 & 4723 & 5079 & 4460 \\
\hline$R(I>3 \sigma(I))$ & 0.042 & 0.036 & 0.038 & 0.089 \\
\hline$R w(I>3 \sigma(I))$ & 0.1220 & 0.1011 & 0.1261 & 0.2336 \\
\hline
\end{tabular}


$\mathrm{O}$ atom of $(+)-18 \mathrm{C} 6 \mathrm{H}_{4}$, because this hydrogen bond is formed only for L-Ser. This is also supported from the energetic preference of the interaction of L-Ser over D-Ser with $(+)-18 \mathrm{C}_{6} \mathrm{H}_{4}$ in $\mathbf{~ L 1}$ and $\mathbf{D 1}$ (Table 5).

\section{Experimental}

HPLC Chiral Separation Analyses The experiments were performed on a Shimadzu LC-10 system with a Shimadzu Chromatopac C-R7A plus data processor, in which the CSP-18C6I column $(2.0 \mathrm{~mm}$ I.D., length $45 \mathrm{~cm})$ was used for the separation: $(+)-18 \mathrm{C} 6 \mathrm{H}_{4}$ was chemically immobilized on $3-$ aminopropylsilanized silica gel, according to the procedure of Machida et $a l^{5}{ }^{5}$ An aqueous solution containing $1 \mathrm{~mm}$ perchloric acid was used as the mobile phase. Chromatographic runs were performed at flow rate of $0.2 \mathrm{ml} / \mathrm{min}$ and temperature of $0{ }^{\circ} \mathrm{C}$. The sample solution was prepared by dissolving proper amount of $\mathrm{D}-\mathrm{L}-\mathrm{L}-\mathrm{Ser}$ or $\mathrm{D}-\mathrm{L}-\mathrm{L}-\mathrm{ll}$ in $0.5 \mathrm{M} \mathrm{HCl}$, the $1 \mu \mathrm{l}$ volume was injected into the column, and the eluted solution was detected by the absorbance at $200 \mathrm{~nm}$.

X-Ray Crystal Analyses The respective complex crystals were prepared from $0.1 \mathrm{~mol} / 1$ perchloric acid containing an equimolar amount of $(+)-18 \mathrm{C} 6 \mathrm{H}_{4}$ and D-Ser, L-Ser, D-Glu, or L-Glu by the slow evaporation at $293 \mathrm{~K}$. The colorless prism crystals were obtained. X-Ray data were collected with a Rigaku RINT RAPID/R diffract meter by using the graphitemonochromated $\mathrm{Cu} K \alpha$ radiation $(\lambda=1.5418 \AA)$ at $173 \mathrm{~K}$. Details for cell parameter determinations and the data collections are summarized in Table 6 Intensity data within $2 \theta \leqq 136.4^{\circ}$ were measured by employing an imaging plate area detector.

Each crystal structure was solved by the direct method with the SIR-92 program. ${ }^{24)}$ The positional parameters of non- $\mathrm{H}$ atoms were refined by fullmatrix least squares with anisotropic temperature parameters using the CRYSTALS. ${ }^{25}$ The positions of all H-atoms were determined from a difference Fourier map. They were treated as riding with fixed isotropic displacement parameters and were not included as variables for the refinements. Details of structure refinement are also given in Table 6. In the final stage of the refinement, none of the positional parameters of non- $\mathrm{H}$ atoms shifted more than one-third from their estimated standard deviations. All calculations were performed using the Crystal Structure, crystallographic software package. ${ }^{26)}$ The analysis result of D2 was less accurate than the others because of its small and fragile crystal.

The final atomic coordinates, anisotropic temperature factors, bond lengths, bond angles, torsion angles of non- $\mathrm{H}$ atoms, and the atomic coordinates of $\mathrm{H}$ atoms have been deposited with the following designations: L1 CCDC 282940, D1: CCDC 282941, L2: CCDC 282942, D2: CCDC 282943. These can be obtained free of charge at www.ccdc.cam.ac.uk/ conts/retrieving.html (or from the Cambridge Crystallographic Data Centre, 12 Union Road, Cambridge CB2 1EZ, UK; fax: (+44) 1223-336-033; or deposit@ccdc.cam.ac.uk).

Molecular Orbital Calculations To investigate the structural and interaction stabilities of each complex, the heat energy of complex formation and total energy were calculated by the molecular orbital PM3 method ${ }^{27)}$ in MOPAC system (Ver. 6) ${ }^{28)}$ The atomic coordinates from the present X-ray results were used for the calculations. The comparison of each complex was performed by the single point calculations.

\section{References and Notes}

1) Pedersen C. J., J. Am. Chem. Soc., 89, 2495-2496 (1967).

2) Pedersen C. J., J. Am. Chem. Soc., 89, 7017-7036 (1967).

3) Sousa L. R., Sogah G. D. Y., Hofmann D. H., Cram D. J., J. Am. Chem. Soc., 100, 4569-4576 (1978).

4) Sogah G. D. Y., Cram D. J., J. Am. Chem. Soc., 101, 3035-3042 (1979).

5) Machida Y., Nish H., Nakamura K., Nakai H., Sato T., J. Charomatogr $A, \mathbf{8 0 5}, 85-92$ (1998)

6) Kuhn R., Erni F., Bereuter T., Hausler J., Anal. Chem., 64, 2815-2820 (1992).

7) Kuhn R., Steimmetz C., Bereuter T., Hass O., Erni F., J. Chromatogr A, 666, 367-373 (1994).

8) Nishi H., Nakamura K., Nakai H., Sato T., J. Chromatogr. A, 757, 225-235 (1997)

9) Schultz C. L., Moini M., Anal. Chem., 75, 1508-1513 (2003).

10) Machida Y., Nishi H., Nakamura K., J. Chromatogr. A, 810, 33-41 (1998).

11) Myung H. H., Jong S. J., Wonjae L., J. Chromatogr. A, 822, 155-161 (1998).

12) Myung H. H., Hye J. K., Jong S. J., Wonjae L., J. Liq. Chrom. \& Rel Technol., 23, 2669-2682 (2000).

13) Nagata H., Nishi H., Kamigauchi M., Ishida T., Org. Biomol. Chem., 2, 3470-3475 (2004).

14) Gong X. Y., Kuban P. K., Tanyanyiwa J., Hauser P. C., J. Chromatogr. $A, \mathbf{1 0 8 2}, 230-234$ (2005)

15) Kuwahara Y., Nagata H., Nishi H., Tanaka Y., Kakehi K., Chromatographia, 62, 505-510 (2005)

16) Machida Y., Nish H., Nakamura K., Chirality, 11, 173-178 (1999).

17) Frey M. N., Lehmann M. S., Koetzle T. F., Hamilton W. C., Acta Cryst., B29, 876-884 (1973).

18) Kistenmacher T. J., Rand G. A., Marsh R. E., Acta Cryst., B30, 2573-2578 (1974).

19) Moggach S. A., Allan D. R., Morrison C. A., Parsons S., Sawyer L., Acta Cryst., B61, 58-68 (2005).

20) Hirayama N., Shirahata K., Ohashi Y., Sasada Y., Bull. Chem. Soc. Jpn., 53, 30-35 (1980).

21) Bhat T. N., Vijayan M., Acta Cryst., B33, 1754-1759 (1977).

22) Taira Z., Watson W. H., Acta Cryst., B33, 3823-3827 (1977).

23) Cody V., "Chemistry and Biochemistry of the Amino Acids," ed. by Barrett G. C., Chapman and Hall, London, 1984, pp. 625-653.

24) Altomare A., Cascarano G., Giacovazzo C., Guagliardi A., Burla M., Polidori G., Camali M., J. Appl. Cryst., 27, 435 (1994).

25) Program for the Refinement of Crystal Structure, Watkin D. J., Prout C. K., Carruthers J. R., Betterridge P. W., Chemical Crystallography Laboratory, Oxford, U.K., 1999.

26) Crystal Structure Analysis Package. Rigaku and Rigaku/MSC, 9009 New Trails Dr. The Woodlands TX 77381 U.S.A., 2000-2005.

27) Stewart J. J. P., J. Comput. Chem., 10, 209-220 (1989).

28) Stewart J. J. P., QCPE\#455. 